\title{
ON THE COMPUTATIONAL EFFICIENCY OF THE ALGORITHM OF THE NUMERICAL SOLUTION OF OPTIMAL CONTROL PROBLEMS FOR MODELS OF LEONTIEFF TYPE
}

\author{
A. V. Keller, South Ural State University, Chelyabinsk, Russian Federation,
} alevtinak@inbox.ru.

\begin{abstract}
The paper shows the efficiency of the numerical algorithm for the class of problems that is considered by the example of optimal control, hard control, start control and hard starting control for the Leontieff type models. There are presented actual results of computational experiment. As the initial condition is used Showalter - Sidorov condition. This eliminates the restrictions caused by the need to initial checking the data that existed when using Cauchy conditions. The introduction presents various problems of optimal control. Is given their economic interpretation. The first section presents a theorem an existence of a unique solution the problem of optimal control, kind of exact and approximate solutions, the main stages of the algorithm for finding approximate solutions, theorem on the convergence of the approximate solution to the exact one. The second section presents the results of a computational experiment of solving the problem of optimal control. The third section presents the results of a computational experiment of solving the problem of hard control. The fourth section contains the results of numerical experiments solving the problem of start control and the problem of hard starting control. The fifth section presents the results of computational experiments with different parameters of the algorithm as an example a model of Leontieff type. It is shown that the change of parameters leads to small computational error, indicating the computational efficiency.
\end{abstract}

Keywords: numerical solution, optimal control, Liontief type models, computational effiency of the algorithm.

\section{Introduction}

Let $L$ and $M$ - be square matrices of $\operatorname{order} n, \operatorname{det} L=0, M$ is $(L, p)$-regular [1]. Consider the Showalter - Sidorov problem

$$
\left[R_{\mu}^{L}(M)\right]^{p+1}\left(x(0)-x_{0}\right)=0
$$

for an inhomogeneous linear system

$$
L \dot{x}=M x+y,
$$

where $\operatorname{det} L=0$, and vector-function $y:[0 ; \tau] \rightarrow \mathbb{R}^{n}, \tau \in \mathbb{R}_{+}$.

Systems of the form (2) with condition $\operatorname{det} L=0$ does not have a common name. So in [2] they are called algebraic differential equations, in [3] are called differential-algebraic equations, in [4] are called degenerate systems of ordinary differential equations. The first type of system (2) was proposed to call Leontieff type system in [5] referring to its prototype - the famous dynamic Leontieff model with the balance equation [9]. Later, similar systems have arisen in the problems of hydrodynamics [6], metrology [7] and economy [8]. The first W. Leontieff investigated the system (2) unsolved relative to derivative. Therefore 
in this paper, we use the name - Leontieff type system, considering that it and all of the above are synonyms. At the same time, the Leontieff type system are a special case of equations of Sobolev type [10], so such name, on the one hand, allows you to briefly observe the condition of the degeneracy of the system, on the other hand - retains some terminological tradition. Notice that in the terms "Leontieff type system" and "Leontieff type models" is embedded different meanings. The term "Leontieff type system" will be used in relation to (2) as a mathematical object. When using "Leontieff type system" in particular application we will talk about the Leontieff type models. So for formulating the Showalter-Sidorov problem for Leontieff type model (degenerate dynamic balance model) is necessary add conditions

$$
x(t) \geq 0, f(t) \leq 0, t \in[0, \tau] .
$$

The $x_{j}(t)$ is production output of sector $j, j=\overline{1, n}$. Their nonnegativity caused by economic sense. Nonpositivity $f_{i}(t)=-g_{i}(t)$ is due to non-negative finite demand $g_{i}(t)$ of the industry's products $i, i=\overline{1, n}$. And finally a dynamic balance model

$$
x(t)=A x(t)+L \dot{x}+g(t)
$$

leads to "Leontieff type system".

For statement the problem of optimal control and the problem of hard control, we introduce control space

$$
\mathfrak{U}=\left\{\text { and } \in L_{2}\left((0, \tau) ; \mathbb{R}^{n}\right): u^{(p+1)} \in L_{2}\left((0, \tau) ; \mathbb{R}^{n}\right), \quad p \in\{0\} \cup \mathbb{N}\right\} .
$$

and state space

$$
\mathcal{X}=\left\{x \in L_{2}\left((0, \tau) ; \mathbb{R}^{n}\right): \dot{x} \in L_{2}\left((0, \tau) ; \mathbb{R}^{n}\right)\right\} .
$$

In the space $\mathfrak{U}$ select compact convex set $\mathfrak{U}_{\partial}$. It is set of admissible controls.

Pose the problem of optimal control for a Leontieff type system. Find a pair of $(v, x(v)) \in \mathfrak{U}_{\partial} \times \mathcal{X}$ almost everywhere on $(0, \tau)$ satisfying Leontieff type system.

$$
L \dot{x}=M x+f+B u,
$$

with Showalter - Sidorov intial condition (1), at that

$$
\begin{gathered}
J(v)=\min _{u \in \mathfrak{U}_{\partial}} J(u), \\
J(u)=\beta \sum_{q=0}^{1} \int_{0}^{\tau}\left|C x^{(q)}(u, t)-C x_{0}^{(q)}(t)\right|^{2} d t+(1-\beta) \sum_{q=0}^{\theta} \int_{0}^{\tau}\left\langle N_{q} u^{(q)}(t), u^{(q)}(t)\right\rangle d t,
\end{gathered}
$$

here $|\cdot|$ and $\langle\cdot\rangle$ is the norm and scalar product in $\mathbb{R}^{n}$ respectively, $C$ is square matrix of order $n, N_{q}$ are symmetric positive definite matrices, $q=\overline{0, p+1}, \theta=\overline{0, p+1}$. Consider the problem (1), (4) - (6) as Leontieff type model - dynamic balance model of an enterprise. Let us assume: 1) the initial state of the system is the gross production of the previous period, subject to a going concern; 2) criterion of efficiency of control is to achieve the target values of some indicators $C x_{0}(t)$ considering the amount of control. Cost functional takes the form

$$
J(u)=\beta \sum_{q=0}^{1} \int_{0}^{\tau}\left|C x^{(q)}(u, t)-C x_{0}^{(q)}(t)\right|^{2} d t+(1-\beta) \sum_{q=0}^{1} \int_{0}^{\tau}\left\langle N_{q} u^{(q)}(t), u^{(q)}(t)\right\rangle d t
$$


due to the economic sense. Where $\beta$ are weight coefficients control objectives to achieve targets, $1-\beta$ are weight coefficients to minimize the control, $\theta=1$. Moreover, add conditions

$$
\begin{gathered}
x_{i}(v, t) \geq w_{i} \geq 0, \quad i=1,2, \ldots, n, \\
f(t) \leq 0,
\end{gathered}
$$

here $w_{i}$ are lower limits of values of gross output that the minimum necessary for the operation of the economic system. As the set of admissible controls we put

$$
\sum_{q=0}^{p+1} \int_{0}^{\tau}\left|u^{(q)}(t)\right|^{2} d t \leq d .
$$

\section{The problem of hard controls.}

Find a pair $(v, x(v)) \in \mathfrak{U}_{\partial} \times \mathcal{X}$ almost everywhere on $(0, \tau)$ satisfying the Leontieff type system (4) with Showalter - Sidorov intial condition (1), is satisfied here (5), where the cost functional has the form

$$
J(u)=\sum_{q=0}^{1} \int_{0}^{\tau}\left|C x^{(q)}(u, t)-C x_{0}^{(q)}(t)\right|^{2} d t .
$$

Consider the problem of hard controls (1), (4), (5), (11) as Leontieff type model degenerate dynamic balance model of the enterprise. Let us assume: 1) the initial state of the system is the gross production of the previous period, subject to a going concern; 2) criterion of efficiency of control is only the achievement of the target values of the indicators $C x_{0}(t)$, wherein the amount of control in the current moment of time may be any that provides a plan. Given the economic sense to add conditions (8) and (9), set of admissible controls has the form (10). In addition to the application of economic problem of hard controls holds technical annex that is opening a promising direction of research in the theory and practice of dynamic measurements [12], [13].

For statement the problem of start control and the problem of hard starting control, we introduce

$$
\mathfrak{Y}=\left\{y \in L_{2}\left((0, \tau) ; \mathbb{R}^{n}\right): y^{(p+1)} \in L_{2}\left((0, \tau) ; \mathbb{R}^{n}\right), \quad p \in\{0\} \cup \mathbb{N}\right\}
$$

and control space

$$
\mathcal{X}=\left\{x \in L_{2}\left((0, \tau) ; \mathbb{R}^{n}\right): \dot{x} \in L_{2}\left((0, \tau) ; \mathbb{R}^{n}\right)\right\} .
$$

Control space $\mathfrak{U}=\mathbb{R}^{n}$. In the space $\mathfrak{U}$ select compact convex set $\mathfrak{U}_{\partial}^{0}$. It is a set of admissible control

$$
\left|u^{0}\right|^{2} \leq d
$$

The problem of start control.

Find a pair $\left(v_{0}, x\left(v_{0}\right)\right) \in \mathfrak{U}_{\partial}^{0} \times \mathcal{X}$ almost everywhere on $(0, \tau)$ satisfying the Leontieff type system (2) with Showalter - Sidorov intial condition

$$
\left[R_{\mu}^{L}(M)\right]^{p+1}\left(x(0)-u_{0}\right)=0,
$$


furthermore

$$
\begin{gathered}
J\left(v_{0}\right)=\min _{u_{0} \in \mathfrak{U}_{\partial}} J\left(u_{0}\right) \\
J\left(u_{0}\right)=\beta \sum_{q=0}^{1} \int_{0}^{\tau}\left|C x^{(q)}\left(y, u_{0}, t\right)-C x_{0}^{(q)}(t)\right|^{2} d t+(1-\beta)\left|u_{0}\right|^{2} .
\end{gathered}
$$

Consider the problem of start controls (2), (12)-(14) as Leontieff type model - degenerate dynamic balance model of the enterprise. Let us assume: 1) consideration of a newly created enterprise, or emerging from crisis then the initial state of the system is an external influence, provides the necessary supply in the coming period for the company, which it does not have; 2) criterion of efficiency of control is to achieve the target values of some indicators $C x_{0}(t)$ considering the amount of control. Given the economic sense to add conditions (8) and (9).

\section{The problem of hard starting control.}

Find a pair $\left(v_{0}, x\left(v_{0}\right)\right) \in \mathfrak{U}_{\partial}^{0} \times \mathcal{X}$ almost everywhere on $(0, \tau)$ satisfying the Leontieff type system (2) with Showalter - Sidorov intial condition (12), is satisfied here(13), where the cost functional has the form

$$
J\left(u_{0}\right)=\sum_{q=0}^{1} \int_{0}^{\tau}\left|C x^{(q)}\left(y, u_{0}, t\right)-C x_{0}^{(q)}(t)\right|^{2} d t
$$

Consider the problem of hard starting control (2), (12), (13), (15) as Leontieff type model - degenerate dynamic balance model of the enterprise. Let us assume: 1) consideration of a newly created enterprise, or emerging from crisis then the initial state of the system is an external influence, provides the necessary supply in the coming period for the company, which it does not have; 2) criterion of efficiency of control is only the achievement the target values of some indicators $C x_{0}(t)$, wherein the amount of control in the initial moment of time may be any that provides a plan. Given the economic sense to add conditions (8) and (9).

\section{Exact and approximate solution of the problem of optimal control}

This section presents the results of the form of exact and approximate solutions only problem of optimal control for Leontieff type models. The main steps of the algorithm of the numerical solution of this problem are given. For the other tasks of the main stages of the same, the differences are due to the initial state of the conditions and functional quality. A more detailed exposition in [11].

Theorem 1. Let the matrix $M(L, p)$-regular, $p \in \mathbb{N}_{0}, \tau \in \mathbb{R}_{+}$, and the $\operatorname{det} M \neq 0$. Then for any $x_{0} \in \mathbb{R}^{n}, f \in H^{p+1}\left(\mathbb{R}^{n}\right)$ there exists a unique solution $(v, x(v)) \in \mathfrak{U}_{\partial} \times \mathcal{X}$ problem of optimal control (1), (4)-(6), here $v$ is a minimum point of the cost functional(6), and $x(v)$ defined by formula

$$
x(v)=\lim _{k \rightarrow+\infty} x_{k}(v, t)=\lim _{k \rightarrow+\infty}\left[-\sum_{q=0}^{p}\left(M^{-1}\left(I-Q_{k}\right) L\right)^{q} M^{-1}\left(I-Q_{k}\right)(f+B v)^{(q)}(t)+\right.
$$




$$
\left.+X_{k}^{t} x_{0}+\int_{0}^{\tau} R_{k}^{t-s} Q_{k}(f(s)+B v(s)) d s\right]
$$

where

$$
\begin{gathered}
Q_{k}=\left(k L_{k}^{L}(M)\right)^{p+1}, X_{k}^{t}=\left(\left(L-\frac{t}{k} M\right)^{-1} L\right)^{k} \\
R_{k}^{t}=\left(\left(L-\frac{t}{k} M\right)^{-1} L\right)^{k-1}\left(L-\frac{t}{k} M\right)^{-1}
\end{gathered}
$$

To find the approximate solution $u(t)$ we use the representation

$$
u^{\ell}(t)=\operatorname{col}\left(\sum_{j=0}^{\ell} a_{1 j} t^{j}, \ldots, \sum_{j=0}^{\ell} a_{n j} t^{j}\right)
$$

where $\ell \in \mathbb{N}$. Considering the form of first summand in the formula (16) $\ell$ necessary to take so that $\ell>p$.

Let the approximate solution problem of optimal control (1), (4)-(6) denote pair $\left(\tilde{v}_{k}^{\ell}, \tilde{x}_{k}^{\ell}\right)$. The form $(17) u^{\ell}(t)$ substitute in (6) and (16). Then the cost functional takes the form

$$
J_{k}\left(u^{\ell}\right)=\sum_{q=0}^{1} \int_{0}^{\tau}\left|C x_{k}^{(q)}\left(u^{\ell}, t\right)-C x_{0}^{(q)}(t)\right|^{2} d t++\sum_{q=0}^{\theta} \int_{0}^{\tau}\left\langle N_{q}\left(u^{\ell}\right)^{(q)}(t),\left(u^{\ell}\right)^{(q)}(t)\right\rangle d t
$$

moreover, $x_{k}\left(u^{\ell}, t\right)$ takes the form

$$
\begin{aligned}
x_{k}\left(u^{\ell}, t\right)=- & \sum_{q=0}^{p}\left(M^{-1}\left(I-Q_{k}\right) L\right)^{q} M^{-1}\left(I-Q_{k}\right)\left(f+B u^{\ell}\right)^{(q)}(t)+ \\
& +X_{k}^{t} x_{0}+\int_{0}^{t} R_{k}^{t-s} Q_{k}\left(f(s)+B u^{\ell}(s)\right) d s .
\end{aligned}
$$

and $\tilde{v}_{k}^{\ell}$ is a minimum point of the cost functional, i.e.

$$
J\left(\tilde{v}_{k}^{\ell}\right)=\min _{u^{\ell} \in \mathfrak{U}_{\partial}^{l}} J_{k}\left(u^{\ell}\right),
$$

Finding $\tilde{v}_{k}^{\ell}$ substituting for $u^{l}$ in (19) we get $\tilde{x}_{k}^{l}$, ie $\tilde{x}_{k}^{\ell}=x_{k}\left(\tilde{v}_{k}^{\ell}, t\right)$. The pair $(v, x(v))$ is denoted the exact solution, and the pair $\left(\tilde{v}_{k}^{\ell}, \tilde{x}_{k}^{\ell}\right)$ is denoted approximate solution a problem of optimal control.

The algorithm for finding an approximate solution a problem of optimal control reduces to seven stages.

Stage 1. Evaluate $\operatorname{det} M$. Check the value to be different from zero with accuracy $\epsilon=10^{-30}$. In the case of $\operatorname{det} M=0$ is necessary to replace the $z=e^{\lambda t} x$ and continue to find solutions.

Stage 2. Calculate the order of the pole $p=n-q$, where $q=\operatorname{deg} \operatorname{det}(\mu L-M)$. 
Stage 3. The calculation of the number $K$, from which you can calculate the approximate solution $K=\max \left\{k_{1}, k_{2}\right\}$. Here

$$
\begin{gathered}
k_{1}=\frac{1}{\alpha} \sum_{i=0}^{q}\left|a_{i}\right|+1, \quad \alpha=\max \left\{1, \frac{1}{\left|a_{q}\right|} \sum_{i=0}^{q}\left|a_{i}\right|\right\}, \\
k_{2}=\frac{1}{\alpha p^{p}} \sum_{i=0}^{q}\left|a_{i}\right|(p+1)^{n-i}+1 .
\end{gathered}
$$

Stage 4. Given a $\eta$ and integration segment $[0, \tau]$ weights and nodes shall be calculated $\omega_{j}, s_{j}$ of Gauss quadrature formula.

Stage 5. At a given point $\vartheta_{j} \in[0, \tau]$ at zero values $a_{i j}$ from (17) shall be calculated $x_{k}(0, t)$ and $J_{k}(0)$.

Stage 6. Located a minimum cost functional $J\left(\tilde{v}_{k}^{\ell}\right)$ and the minimum point $\tilde{v}_{k}^{\ell}=\operatorname{col}\left(\sum_{j=0}^{\ell} a_{1 j}^{*} t^{j}, \ldots, \sum_{j=0}^{\ell} a_{n j}^{*} t^{j}\right)$. Finding the unknown $a_{i j}^{*}$ comes to the following substeps.

Set the parameters required for the calculation of: maximum step $h_{\max }>0$, minimum step $h_{\min }>0$, value of permissible error calculation of the cost functional $\varsigma>0$, the amount of change step $r \in(0,1)$.

Under the main calculation we understand the procedure of finding the values of the cost functional with an array of coefficients of vector-polynomials $u^{l}$. Assume the following notation:

$-\rho$ is number of iterations of the main calculation, $\rho=0,1, \ldots$;

- $\left(\widehat{a_{i j}}\right)$ are coefficients of vector-polynomials $u^{l}$, forming a matrix $n \times l+1$ and accepted for the calculation of the cost functional at iteration $\rho$, at that $\widehat{a_{i j}^{0}}=0, i=\overline{1, n}, j=\overline{0, l}$;

- $J_{k}\left(\widehat{a_{i j}^{\rho}}\right)$ is an approximate value of the cost functional calculated in iteration $\rho$.

The basic calculation is as long as the condition does not hold

$$
\left|J_{k}\left(\widehat{a_{i j}^{\rho}}\right)-J_{k}\left(\widehat{a_{i j}^{\rho-1}}\right)\right|<\varsigma .
$$

When major achievement the necessary precision calculation accept

$$
a_{i j}^{*}=\widehat{a_{i j}^{\rho}}, i=\overline{1, n}, j=\overline{0, \ell}
$$

and

$$
J_{k}\left(\tilde{v}_{k}^{\ell}\right)=J_{k}\left(\widehat{a_{i j}^{\rho}}\right)
$$

In the same way the value $\tilde{v}_{k}^{\ell}$ found.

Now consider the procedure of finding coefficients $\widehat{a_{i j}^{\rho}}$ in one iteration of the main calculation, denoting $a_{i} j=\widehat{a_{i j}^{\rho-1}}, J=J_{k}\left(\widehat{a_{i j}^{\rho-1}}\right)$. In each, starting with the first and consistently to the last (forward scheme), line of the array of coefficients of vectorpolynomials $u^{l}$ determined coefficient $\widehat{a_{i \xi}}$ to be changed. For convenience, the present procedure by the example of the first row.

The first element of the array $a_{10}$ is changed at constant values of the remaining elements: 
1) $a_{10}^{(1+)}=a_{10}+h_{\max }$ and $a_{10}^{(1-)}=a_{10}-h_{\max }$. For each of these two values is calculated value of the functional $J_{10}^{(1+)}$ and $J_{10}^{(1-)}$.

If $J_{10}^{(1+)}>J$ and $J_{10}^{(1-)}>J$, then the value $a_{10}$ can not be changed. The transition to the element $a_{11}$.

2) If $J_{10}^{(1+)}<J\left(J_{10}^{(1-)}<J\right)$, then $J_{10}^{(1 s)}=J_{10}^{(1+)}\left(J_{10}^{(1 s)}=J_{10}^{(1-)}\right)$ and $a_{10}^{(1 s)}=a_{10}^{(1+)}$ $\left(a_{10}^{(1 s)}=a_{10}^{(1-)}\right)$. Then, change the value of the item $a_{10}^{(1 s)}: a_{10}^{(2+)}=a_{10}^{(1 s)}+h_{\max } \cdot r$ and $a_{10}^{(2-)}=a_{10}^{(1 s)}-h_{\max } \cdot r$. If $J_{10}^{(2+)}>J_{10}^{(1 s)}$ and $J_{10}^{(2-)}>J_{10}^{(1 s)}$, then $\widehat{a_{10}}=a^{(1 s)}$ and $J=J_{10}^{(1 s)}$. Then transition to the element $a_{11}$.

3) If $J_{10}^{(2+)}<J_{10}^{(1 s)}\left(J_{10}^{(2-)}<J_{10}^{(1 s)}\right)$, then $J_{10}^{(2 s)}=J_{10}^{(2+)}\left(J_{10}^{(2 s)}=J_{10}^{(2-)}\right)$ and $a_{10}^{(2 s)}=a_{10}^{(2+)}$ $\left(a_{10}^{(2 s)}=a_{10}^{(2-)}\right)$. Then, change the value of the item $a_{10}^{(2 s)}$ etc. when values are changed $a_{10}^{(h+)}=a_{10}^{(h-1, s)}+h_{\max } \cdot r^{h-1}$ and $a_{10}^{(h-)}=a_{10}^{(h-1, s)}-h_{\max } \cdot r^{h-1}$ while either $h_{\max } \cdot r^{h-1}<h_{\min }$ or not fulfilled the condition of belonging to the set of admissible controls or it moves to the next item line.

The next element in the array $a_{11}$ varies with the original meaning of all other elements, ie even if the change was an element $a_{10}$ in the implementation of the procedure for the calculation of the element $a_{11}$ then it is not considered. Takes consideration only reduced (if it happened) value of the functional quality $J$. Procedure of changing element $a_{11}$ is similar to the procedure of changing $a_{10}$. And so all the elements of the first row. It is then determined for what value $\widehat{a_{1 j}}$ the value $J$ obtained after the loop on the elements of the first row. We denote this element $\widehat{a_{1 \xi}}$. Only it shall be change in the array.

Turning to loop through the second line, the first received update value for one element and calculations are continuing.

As a result, we get a new array, in which each line is changed one element. It is precisely this array is used in the main calculation.

Note that the calculation for each row is fixed $\Delta_{i}$ to the step at which the lowest value of the cost functional is achieved. And with the next iteration of changing elements in the $i$ does not begin with $h_{\max }$ and since $\Delta_{i}$, which significantly increases the speed of calculations.

Stage 7. Calculation of the $\tilde{x}_{k}^{\ell}$.

When discussing the algorithm, it should be emphasized that algorithm can be improved by using the parallelization process: the choice variable elements in the rows can be done by comparing the changes in all lines at the same time.

Theorem 2. Let the matrix $M(L, p)$-regular, $p \in \mathbb{N}_{0}$, $\operatorname{det} M \neq 0$. Functional (6) is a continuous, strongly convex function on a compact convex set $\mathfrak{U}_{\partial} \subset \mathfrak{U}$. Let $(v, x(v))$ is exact solution and $\left(\tilde{v}_{k}^{l}, \tilde{x}_{k}^{l}\right)$ is approximate solution the problem of optimal control (1), (4)-(6). Then the sequence $\left\{\tilde{v}_{k}^{l}\right\}$ converges to $\{v\}$ in the norm $\mathfrak{U}$, the sequence $\left\{\tilde{x}_{k}^{l}\right\}$ converges to $x(v)$ in the norm $\mathcal{X}$ with $k \rightarrow \infty, l \rightarrow \infty$, at that $J_{k}\left(\tilde{v}_{k}^{l}\right) \rightarrow J(v)$, and following inequality holds

$$
q\left|\tilde{v}_{k}^{l}-v\right|^{2} \leq J_{k}\left(\tilde{v}_{k}^{l}\right)-J(v)
$$




\section{The problem of optimal control}

We presented the results of a computational experiment of solving the problem of optimal control for Leontieff type model represented by Granberg example,

$$
\begin{gathered}
L=\left(\begin{array}{ccc}
1,5 & 1,6 & 0,9 \\
0 & 0 & 0 \\
0 & 0 & 0
\end{array}\right), \quad M=\left(\begin{array}{ccc}
0,9 & -0,116 & -0,075 \\
-0,5 & 0,452 & -0,425 \\
0 & 0 & 1
\end{array}\right), \\
x_{0}=\left(\begin{array}{c}
18 \\
50 \\
32
\end{array}\right), \quad x_{0}(t)=\left(\begin{array}{c}
18+t \\
50+t \\
32+10 t
\end{array}\right), \\
y(t)=\left(\begin{array}{c}
0 \\
0 \\
-35-10 t
\end{array}\right), \quad W=\left(\begin{array}{c}
15 \\
20 \\
25
\end{array}\right) .
\end{gathered}
$$

The $B, N_{0}, N_{1}$ and $C$ are taken as an identity matrices, $\beta=0,5$.

Table 1

Numerical solution $\tilde{x}_{k}^{\ell}\left(t_{j}\right)$ of the control problem

\begin{tabular}{|c|c|c|c|}
\hline $\mathrm{t}$ & $\tilde{x}_{k 1}\left(v^{\ell}, t\right)$ & $\tilde{x}_{k 2}\left(v^{\ell}, t\right)$ & $\tilde{x}_{k 3}\left(v^{\ell}, t\right)$ \\
\hline 0 & $1.800000 \mathrm{e}+001$ & $5.000000 \mathrm{e}+001$ & $3.200000 \mathrm{e}+001$ \\
\hline $1 / 12$ & $2.751818 \mathrm{e}+001$ & $6.332537 \mathrm{e}+001$ & $3.583118 \mathrm{e}+001$ \\
\hline $1 / 6$ & $2.470681 \mathrm{e}+001$ & $6.018744 \mathrm{e}+001$ & $3.665609 \mathrm{e}+001$ \\
\hline $1 / 4$ & $2.221789 \mathrm{e}+001$ & $5.740677 \mathrm{e}+001$ & $3.747681 \mathrm{e}+001$ \\
\hline $1 / 3$ & $2.006371 \mathrm{e}+001$ & $5.500021 \mathrm{e}+001$ & $3.829514 \mathrm{e}+001$ \\
\hline $5 / 12$ & $1.826219 \mathrm{e}+001$ & $5.298982 \mathrm{e}+001$ & $3.911256 \mathrm{e}+001$ \\
\hline $1 / 2$ & $1.683437 \mathrm{e}+001$ & $5.139993 \mathrm{e}+001$ & $3.993024 \mathrm{e}+001$ \\
\hline $7 / 12$ & $1.580214 \mathrm{e}+001$ & $5.025427 \mathrm{e}+001$ & $4.074906 \mathrm{e}+001$ \\
\hline $2 / 3$ & $1.518604 \mathrm{e}+001$ & $4.957326 \mathrm{e}+001$ & $4.156963 \mathrm{e}+001$ \\
\hline $3 / 4$ & $1.500312 \mathrm{e}+001$ & $4.937138 \mathrm{e}+001$ & $4.239231 \mathrm{e}+001$ \\
\hline $5 / 6$ & $1.526507 \mathrm{e}+001$ & $4.965459 \mathrm{e}+001$ & $4.321728 \mathrm{e}+001$ \\
\hline $11 / 12$ & $1.597626 \mathrm{e}+001$ & $5.041794 \mathrm{e}+001$ & $4.404455 \mathrm{e}+001$ \\
\hline 1 & $1.713202 \mathrm{e}+001$ & $5.164325 \mathrm{e}+001$ & $4.487402 \mathrm{e}+001$ \\
\hline
\end{tabular}

Vector-polynomials of control have the form

$$
\begin{gathered}
\tilde{v}_{k 1}^{\ell}=0,001316071-2,539654 t+5 t^{2}-0,502224 t^{3}+0,2392578 t^{4}-0,01852036 t^{7}, \\
\tilde{v}_{k 2}^{\ell}=-0,00007629395+4,374523 t-0,3449441 t^{3}+0,135498 t^{4}+0,15625 t^{6}-0,02653122 t^{7}, \\
\tilde{v}_{k 3}^{\ell}=-0,021286011 t+0,625 t^{2}-0,7441521 t^{3}+0,2758789 t^{4}-0,0094604491 t^{7} .
\end{gathered}
$$

The calculation results $\tilde{v}_{k}^{\ell}\left(t_{j}\right)$ in the set points shown in Table 2 .

Figure 1 shows the planned value $x_{0}(t)$ and approximate solutions of $\tilde{x}_{k}\left(v^{l}, t\right)$ the problem of optimal control for Leontieff type model (Granberg example).

Present the results of computational experiments with the matrix $B$ is different from the identity. The economic meaning of the elements of the matrix $B$ consists of the 
Table 2

Numerical solution $\tilde{v}_{k}^{\ell}\left(t_{j}\right)$ of the control problem

\begin{tabular}{|c|c|c|c|}
\hline$t_{j}$ & $\tilde{v}_{k 1}^{l}$ & $\tilde{v}_{k 2}^{\ell}$ & $\tilde{v}_{k 3}^{\ell}$ \\
\hline 0 & 0 & 0 & 0 \\
\hline $1 / 12$ & $-1.785108 \mathrm{e}-001$ & $3.642743 \mathrm{e}-001$ & $2.149104 \mathrm{e}-003$ \\
\hline $1 / 6$ & $-2.878434 \mathrm{e}-001$ & $7.275217 \mathrm{e}-001$ & $1.058113 \mathrm{e}-002$ \\
\hline $1 / 4$ & $-3.306433 \mathrm{e}-001$ & $1.088731 \mathrm{e}+000$ & $2.319070 \mathrm{e}-002$ \\
\hline $1 / 3$ & $-3.079673 \mathrm{e}-001$ & $1.447197 \mathrm{e}+000$ & $3.818951 \mathrm{e}-002$ \\
\hline $5 / 12$ & $-2.206084 \mathrm{e}-001$ & $1.802533 \mathrm{e}+000$ & $5.410192 \mathrm{e}-002$ \\
\hline $1 / 2$ & $-6.911203 \mathrm{e}-002$ & $2.154770 \mathrm{e}+000$ & $6.975651 \mathrm{e}-002$ \\
\hline $7 / 12$ & $1.461967 \mathrm{e}-001$ & $2.504495 \mathrm{e}+000$ & $8.427233 \mathrm{e}-002$ \\
\hline $2 / 3$ & $4.251734 \mathrm{e}-001$ & $2.852997 \mathrm{e}+000$ & $9.703850 \mathrm{e}-002$ \\
\hline $3 / 4$ & $7.677984 \mathrm{e}-001$ & $3.202433 \mathrm{e}+000$ & $1.076858 \mathrm{e}-001$ \\
\hline $5 / 6$ & $1.174103 \mathrm{e}+000$ & $3.556007 \mathrm{e}+000$ & $1.160491 \mathrm{e}-001$ \\
\hline $11 / 12$ & $1.644076 \mathrm{e}+000$ & $3.918152 \mathrm{e}+000$ & $1.221187 \mathrm{e}-001$ \\
\hline 1 & $2.177544 \mathrm{e}+000$ & $4.294720 \mathrm{e}+000$ & $1.259804 \mathrm{e}-001$ \\
\hline
\end{tabular}

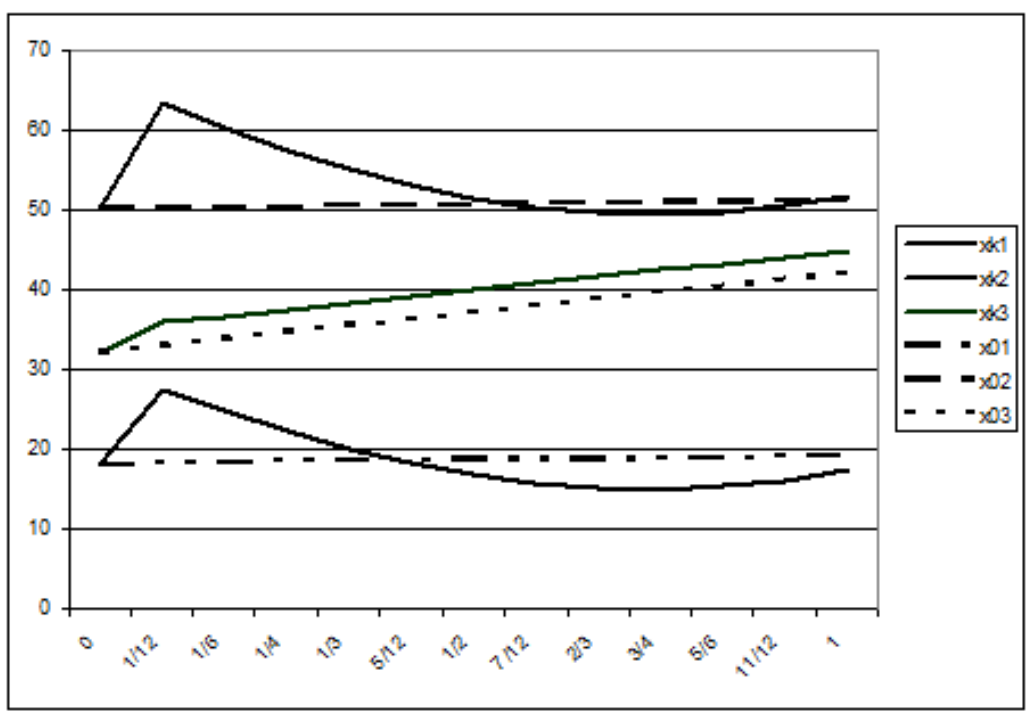

Fig. 1. The results of solving the problem of optimal control for Leontieff type model (Granberg example)

following: $b_{i j}$ is proportion of control in the direction of activity (industry) $i$ from the direction of activity (industry) $j, i, j=\overline{1, n}$. Let the matrix $B$ has the form:

$$
B=\left(\begin{array}{ccc}
1 & 0,25 & 0,15 \\
0 & 0,75 & 0 \\
0 & 0 & 0,85
\end{array}\right)
$$

Its values are the following redistribution of control action (donations or withdrawal) from the the first industry nothing is withdrawn from the second industry is taken 25 percent of the cash value equal to the volume of its gross output and remains within 75 percent, from the third industry is withdrawn 15 percent and remains 85 . Take this matrix for computing 
experiment for Granberg example. We obtain the following results. Vector-polynomials of control have the form

$$
\begin{gathered}
\tilde{v}_{k 1}^{\ell}=-0,0164-1,75 t+0,4 t^{2}-0,019072^{3}+0,088 t^{4}+0,01 t^{5}-0,02 t^{7}, \\
\tilde{v}_{k 2}^{\ell}=1,28 t+2 t^{2}-0,09552 t^{3}+0,02 t^{5}++0,02 t^{7} \\
\tilde{v}_{k 3}^{\ell}=-1,242 t+1,9704 t^{2}-0,02128 t^{3}+0,04 t^{4}+0,01 t^{5}+0,02 t^{7} .
\end{gathered}
$$

The calculation results in the set points shown in Table 3.

Table 3

Numerical solution $\tilde{v}_{k}^{\ell}\left(t_{j}\right)$ of the control problem, $B \neq \mathbb{I}$

\begin{tabular}{|c|c|c|c|}
\hline$t_{j}$ & $\tilde{v}_{k 1}^{\ell}$ & $\tilde{v}_{k 2}^{\ell}$ & $\tilde{v}_{k 3}^{\ell}$ \\
\hline 0 & 0 & 0 & 0 \\
\hline $1 / 12$ & $-1.594623 \mathrm{e}-001$ & $1.205004 \mathrm{e}-001$ & $-8.982701 \mathrm{e}-002$ \\
\hline $1 / 6$ & $-2.969746 \mathrm{e}-001$ & $2.684493 \mathrm{e}-001$ & $-1.523330 \mathrm{e}-001$ \\
\hline $1 / 4$ & $-4.288433 \mathrm{e}-001$ & $4.435283 \mathrm{e}-001$ & $-1.875153 \mathrm{e}-001$ \\
\hline $1 / 3$ & $-5.548585 \mathrm{e}-001$ & $6.454426 \mathrm{e}-001$ & $-1.953107 \mathrm{e}-001$ \\
\hline $5 / 12$ & $-6.746803 \mathrm{e}-001$ & $8.739406 \mathrm{e}-001$ & $-1.755812 \mathrm{e}-001$ \\
\hline $1 / 2$ & $-7.878153 \mathrm{e}-001$ & $1.128841 \mathrm{e}+000$ & $-1.280913 \mathrm{e}-001$ \\
\hline $7 / 12$ & $-8.935834 \mathrm{e}-001$ & $1.410072 \mathrm{e}+000$ & $-5.247398 \mathrm{e}-002$ \\
\hline $2 / 3$ & $-9.910697 \mathrm{e}-001$ & $1.717724 \mathrm{e}+000$ & $5.181681 \mathrm{e}-002$ \\
\hline $3 / 4$ & $-1.079060 \mathrm{e}+000$ & $2.052118 \mathrm{e}+000$ & $1.855715 \mathrm{e}-001$ \\
\hline $5 / 6$ & $-1.155954 \mathrm{e}+000$ & $2.413897 \mathrm{e}+000$ & $3.499091 \mathrm{e}-001$ \\
\hline $11 / 12$ & $-1.219663 \mathrm{e}+000$ & $2.804136 \mathrm{e}+000$ & $5.463843 \mathrm{e}-001$ \\
\hline 1 & $-1.267472 \mathrm{e}+000$ & $3.224480 \mathrm{e}+000$ & $7.771200 \mathrm{e}-001$ \\
\hline
\end{tabular}

Comparing the results shown in Tables 2 and 3 should be concluded that the transfers between sectors leads to the fact that the first industry is becoming the subsidized entire analyzed period, as well as subsidies in the first half of the year will need a third sector considering the planned increase in its volume final product. The surplus second sector are determined by value of positive control. This indicates a possible allocation of resources from the second sector to the third sector of industry. Let us estimate that, what will the redistribution of funds to the value of total output (Table 4).

In the first half of the year has a positive effect of the redistribution on the volume of production. For each of the sectors effect is more in the nonidentity matrix $B$. And since the second half of the year there is a reduction of this index across all sectors. Using a constant matrix does not allow the flexibility to solve the problem of internal redistribution, revealing only the magnitude of subsidies needed.

The computational experiments increase cash outflows from the second and third sectors to the first does not lead to improved results, and even planned targets for the third sector will not be achieved.

\section{The problem of hard control}

We presented the results of a computational experiment of solving the problem of hard control for Leontieff type model represented by Granberg. 
Table 4

Numerical solution $\tilde{x}_{k}\left(v^{l}, t\right)$ of the control problem, $B \neq \mathbb{I}$

\begin{tabular}{|c|c|c|c|}
\hline $\mathrm{t}$ & $\tilde{x}_{k 1}\left(v^{\ell}, t\right)$ & $\tilde{x}_{k 2}\left(v^{\ell}, t\right)$ & $\tilde{x}_{k 3}\left(v^{\ell}, t\right)$ \\
\hline 0 & $1.800000 \mathrm{e}+001$ & $5.000000 \mathrm{e}+001$ & $3.200000 \mathrm{e}+001$ \\
\hline $1 / 12$ & $2.654160 \mathrm{e}+001$ & $6.292487 \mathrm{e}+001$ & $3.590969 \mathrm{e}+001$ \\
\hline $1 / 6$ & $2.456533 \mathrm{e}+001$ & $6.132675 \mathrm{e}+001$ & $3.679615 \mathrm{e}+001$ \\
\hline $1 / 4$ & $2.269935 \mathrm{e}+001$ & $5.978378 \mathrm{e}+001$ & $3.765939 \mathrm{e}+001$ \\
\hline $1 / 3$ & $2.095666 \mathrm{e}+001$ & $5.831077 \mathrm{e}+001$ & $3.849935 \mathrm{e}+001$ \\
\hline $5 / 12$ & $1.935749 \mathrm{e}+001$ & $5.693043 \mathrm{e}+001$ & $3.931591 \mathrm{e}+001$ \\
\hline $1 / 2$ & $1.793158 \mathrm{e}+001$ & $5.567573 \mathrm{e}+001$ & $4.010888 \mathrm{e}+001$ \\
\hline $7 / 12$ & $1.672033 \mathrm{e}+001$ & $5.459233 \mathrm{e}+001$ & $4.087794 \mathrm{e}+001$ \\
\hline $2 / 3$ & $1.577902 \mathrm{e}+001$ & $5.374077 \mathrm{e}+001$ & $4.162262 \mathrm{e}+001$ \\
\hline $3 / 4$ & $1.517884 \mathrm{e}+001$ & $5.319866 \mathrm{e}+001$ & $4.234226 \mathrm{e}+001$ \\
\hline $5 / 6$ & $1.500900 \mathrm{e}+001$ & $5.306269 \mathrm{e}+001$ & $4.303591 \mathrm{e}+001$ \\
\hline $11 / 12$ & $1.537870 \mathrm{e}+001$ & $5.345066 \mathrm{e}+001$ & $4.370224 \mathrm{e}+001$ \\
\hline 1 & $1.641918 \mathrm{e}+001$ & $5.450331 \mathrm{e}+001$ & $4.433945 \mathrm{e}+001$ \\
\hline
\end{tabular}

Vector-polynomials of control have the form

$$
\begin{gathered}
\tilde{v}_{k 1}^{\ell}=5 t+5 t^{2}-0,9164429 t^{3}+0,9667969 t^{4}-0,01876831 t^{7}, \\
\tilde{v}_{k 2}^{\ell}=8,28125 t-1,189575 t^{3}+0,5078125 t^{4}+0,15625 t^{6}-0,05916595 t^{7}, \\
\tilde{v}_{k 3}^{\ell}=-3,4375 t+0,625 t^{2}-1,487427 t^{3}+0,6347656 t^{4}-0,01953125 t^{6}-0,1441193 t^{7} .
\end{gathered}
$$

Hard control allows integrally better achieve targets of gross output, as evidenced by the results shown in the table 6.7. At that the value of the cost functional in the problem of hard control twice as much cost functional in problem of optimal control.

Table 5

Numerical solution $\tilde{x}_{k}\left(v^{\ell}, t\right)$ problem of the hard control

\begin{tabular}{|c|c|c|c|}
\hline $\mathrm{t}$ & $\tilde{x}_{k 1}\left(v^{\ell}, t\right)$ & $\tilde{x}_{k 2}\left(v^{\ell}, t\right)$ & $\tilde{x}_{k 3}\left(v^{\ell}, t\right)$ \\
\hline 0 & $1.800000 \mathrm{e}+001$ & $5.000000 \mathrm{e}+001$ & $3.200000 \mathrm{e}+001$ \\
\hline $1 / 12$ & $2.668857 \mathrm{e}+001$ & $6.195633 \mathrm{e}+001$ & $3.611628 \mathrm{e}+001$ \\
\hline $1 / 6$ & $2.274854 \mathrm{e}+001$ & $5.712685 \mathrm{e}+001$ & $3.722862 \mathrm{e}+001$ \\
\hline $1 / 4$ & $1.966941 \mathrm{e}+001$ & $5.326532 \mathrm{e}+001$ & $3.834109 \mathrm{e}+001$ \\
\hline $1 / 3$ & $1.741387 \mathrm{e}+001$ & $5.033933 \mathrm{e}+001$ & $3.945707 \mathrm{e}+001$ \\
\hline $5 / 12$ & $1.593343 \mathrm{e}+001$ & $4.830192 \mathrm{e}+001$ & $4.057933 \mathrm{e}+001$ \\
\hline $1 / 2$ & $1.516054 \mathrm{e}+001$ & $4.708286 \mathrm{e}+001$ & $4.171019 \mathrm{e}+001$ \\
\hline $7 / 12$ & $1.500107 \mathrm{e}+001$ & $4.658033 \mathrm{e}+001$ & $4.285170 \mathrm{e}+001$ \\
\hline $2 / 3$ & $1.532701 \mathrm{e}+001$ & $4.665296 \mathrm{e}+001$ & $4.400604 \mathrm{e}+001$ \\
\hline $3 / 4$ & $1.596925 \mathrm{e}+001$ & $4.711223 \mathrm{e}+001$ & $4.517594 \mathrm{e}+001$ \\
\hline $5 / 6$ & $1.671067 \mathrm{e}+001$ & $4.771516 \mathrm{e}+001$ & $4.636531 \mathrm{e}+001$ \\
\hline $11 / 12$ & $1.727917 \mathrm{e}+001$ & $4.815740 \mathrm{e}+001$ & $4.758001 \mathrm{e}+001$ \\
\hline 1 & $1.734082 \mathrm{e}+001$ & $4.806655 \mathrm{e}+001$ & $4.882881 \mathrm{e}+001$ \\
\hline
\end{tabular}


The results of calculation $\tilde{v}_{k}^{l}\left(t_{j}\right)$ at fixed points $t_{j}$ shown in Table 6 and show that better achieve planned targets should be more control action, it increases the period of the first industry of subsidies, and the third industry becomes subsidy for the year. The source of the subsidies is the second industry. The profitability of the second sector provides the necessary subsidies and for the first and second industry which also indicates the adequacy of the model under investigation - for a closed economic system can not be otherwise.

Table 6

Numerical solution $\tilde{v}_{k}^{\ell}\left(t_{j}\right)$ problem of the hard control

\begin{tabular}{|c|c|c|c|}
\hline$t_{j}$ & $\tilde{v}_{k 1}^{\ell}$ & $\tilde{v}_{k 2}^{\ell}$ & $\tilde{v}_{k 3}^{\ell}$ \\
\hline 0 & 0 & 0 & 0 \\
\hline $1 / 12$ & $-3.824282 \mathrm{e}-001$ & $6.894403 \mathrm{e}-001$ & $-2.829482 \mathrm{e}-001$ \\
\hline $1 / 6$ & $-6.979413 \mathrm{e}-001$ & $1.375096 \mathrm{e}+000$ & $-5.619529 \mathrm{e}-001$ \\
\hline $1 / 4$ & $-9.480440 \mathrm{e}-001$ & $2.053744 \mathrm{e}+000$ & $-8.410876 \mathrm{e}-001$ \\
\hline $1 / 3$ & $-1.133126 \mathrm{e}+000$ & $2.722815 \mathrm{e}+000$ & $-1.123735 \mathrm{e}+000$ \\
\hline $5 / 12$ & $-1.252472 \mathrm{e}+000$ & $3.380464 \mathrm{e}+000$ & $-1.412666 \mathrm{e}+000$ \\
\hline $1 / 2$ & $-1.304277 \mathrm{e}+000$ & $4.025646 \mathrm{e}+000$ & $-1.710187 \mathrm{e}+000$ \\
\hline $7 / 12$ & $-1.285674 \mathrm{e}+000$ & $4.658200 \mathrm{e}+000$ & $-2.018365 \mathrm{e}+000$ \\
\hline $2 / 3$ & $-1.192776 \mathrm{e}+000$ & $5.278930 \mathrm{e}+000$ & $-2.339372 \mathrm{e}+000$ \\
\hline $3 / 4$ & $-1.020729 \mathrm{e}+000$ & $5.889672 \mathrm{e}+000$ & $-2.675941 \mathrm{e}+000$ \\
\hline $5 / 6$ & $-7.637904 \mathrm{e}-001$ & $6.493340 \mathrm{e}+000$ & $-3.031979 \mathrm{e}+000$ \\
\hline $11 / 12$ & $-4.154229 \mathrm{e}-001$ & $7.093944 \mathrm{e}+000$ & $-3.413346 \mathrm{e}+000$ \\
\hline 1 & $3.158569 \mathrm{e}-002$ & $7.696571 \mathrm{e}+000$ & $-3.828812 \mathrm{e}+000$ \\
\hline
\end{tabular}

Figure 2 shows the planned value $x_{0}(t)$ and approximate solutions $\tilde{x}_{k}\left(v^{l}, t\right)$ the problem of hard control for Leontieff type model (Granberg example).

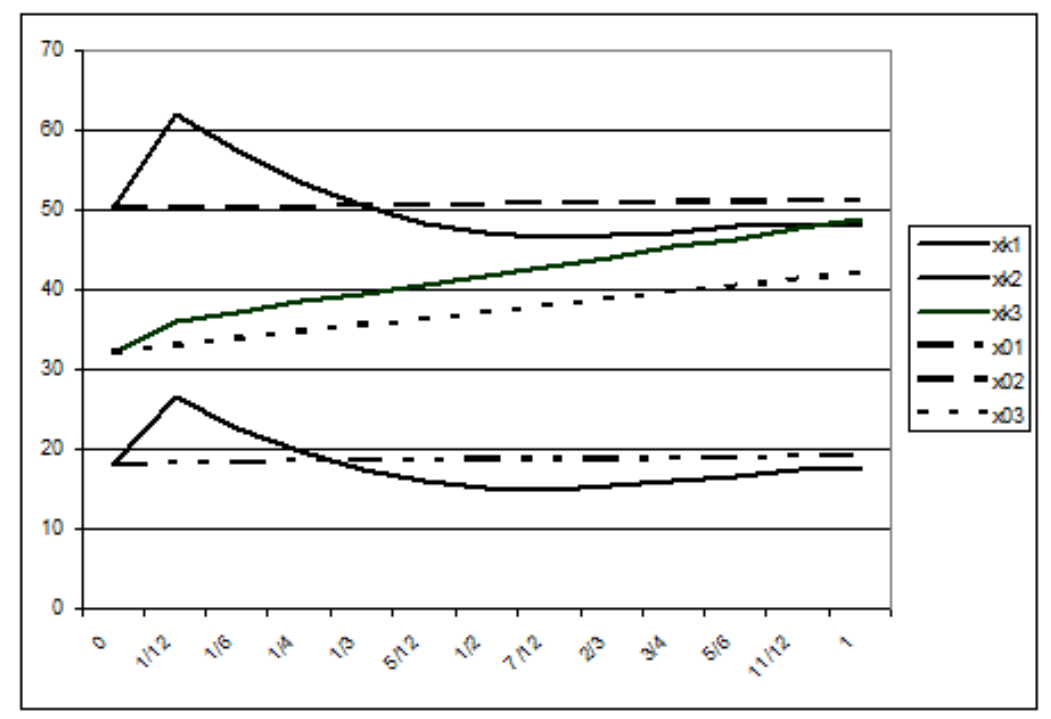

Fig. 2. The results of solving $\tilde{x}_{k}$ the problem of hard control for Leontieff type model (Granberg example) 


\section{The problems of start control and hard starting control.}

We presented the results of a computational experiment of solving the problem of start control for Leontieff type model, represented by W. Leontieff example

$$
\begin{gathered}
L=\left(\begin{array}{ccc}
0,35 & 0,05 & 0,105 \\
0,01 & 0,515 & 0,32 \\
0 & 0 & 0
\end{array}\right), \quad W=\left(\begin{array}{c}
11 \\
11 \\
10,35
\end{array}\right), \\
M=\left(\begin{array}{ccc}
0,75 & -0,2 & -0,55 \\
-0,28 & 0,8589687 & -0,5904998 \\
-0,2666667 & -0,4 & 0,8666667
\end{array}\right), \\
x_{0}(t)=\left(\begin{array}{c}
30+2 t \\
22+5,5 t \\
24+2,5 t
\end{array}\right), \quad y(t)=\left(\begin{array}{c}
-10-1,1 t \\
-25-0,1 t \\
-21-0,37 t
\end{array}\right),
\end{gathered}
$$

the $B, N_{0}, N_{1}$ and $C$ are taken as an identity matrices, $\beta=0,5$.

We represent the solution of a problem of start control for Leontieff example. The values of $\tilde{x}_{k}$ are presented in the table 7 .

Table 7

Numerical solution $\tilde{x}_{k}\left(t_{j}\right)$ the problem of start control

\begin{tabular}{|c|c|c|c|}
\hline $\mathrm{t}$ & $\tilde{x}_{k 1}$ & $\tilde{x}_{k 2}$ & $\tilde{x}_{k 3}$ \\
\hline 0 & $7.09216 \mathrm{e}+001$ & $1.1059226 \mathrm{e}+002$ & $5.837056 \mathrm{e}+001$ \\
\hline $1 / 12$ & $6.178434 \mathrm{e}+001$ & $5.057693 \mathrm{e}+001$ & $6.662011 \mathrm{e}+001$ \\
\hline $1 / 6$ & $5.944481 \mathrm{e}+001$ & $4.657903 \mathrm{e}+001$ & $6.409065 \mathrm{e}+001$ \\
\hline $1 / 4$ & $5.710964 \mathrm{e}+001$ & $4.247533 \mathrm{e}+001$ & $6.151370 \mathrm{e}+001$ \\
\hline $1 / 3$ & $5.475207 \mathrm{e}+001$ & $3.828082 \mathrm{e}+001$ & $5.888794 \mathrm{e}+001$ \\
\hline $5 / 12$ & $5.232077 \mathrm{e}+001$ & $3.402584 \mathrm{e}+001$ & $5.621159 \mathrm{e}+001$ \\
\hline $1 / 2$ & $4.972452 \mathrm{e}+001$ & $2.976574 \mathrm{e}+001$ & $5.348212 \mathrm{e}+001$ \\
\hline $7 / 12$ & $4.680776 \mathrm{e}+001$ & $2.559619 \mathrm{e}+001$ & $5.069582 \mathrm{e}+001$ \\
\hline $2 / 3$ & $4.331173 \mathrm{e}+001$ & $2.167755 \mathrm{e}+001$ & $4.784710 \mathrm{e}+001$ \\
\hline $3 / 4$ & $3.881230 \mathrm{e}+001$ & $1.827391 \mathrm{e}+001$ & $4.492732 \mathrm{e}+001$ \\
\hline $5 / 6$ & $3.262017 \mathrm{e}+001$ & $1.581562 \mathrm{e}+001$ & $4.192303 \mathrm{e}+001$ \\
\hline $11 / 12$ & $2.361937 \mathrm{e}+001$ & $1.500066 \mathrm{e}+001$ & $3.881299 \mathrm{e}+001$ \\
\hline 1 & $1.000414 \mathrm{e}+001$ & $1.695968 \mathrm{e}+001$ & $3.556343 \mathrm{e}+001$ \\
\hline
\end{tabular}

Vector of control has the form

$$
\tilde{v}_{k}=\operatorname{col}(70,9216,105,9226,58,37056) .
$$

In this problem, the value of management has a different meaning, ie, to achieve planned targets starting control of total amount 235,21576 units.

When solving the problem of hard starting components of control have not changed their values:

$$
\tilde{v}_{k}=\operatorname{col}(70,9216,105,9226,58,37056)
$$


Figure 3 presents the results of decisions $\tilde{x}_{k}$ the problem start control. All components of the $\tilde{x}_{k}$ decrease as the initial amount of investment it manifests itself in the first months of operation of the economic system. And as in the future control of the system does not, then it gradually outliving itself, although the integral value of planned targets achieved.

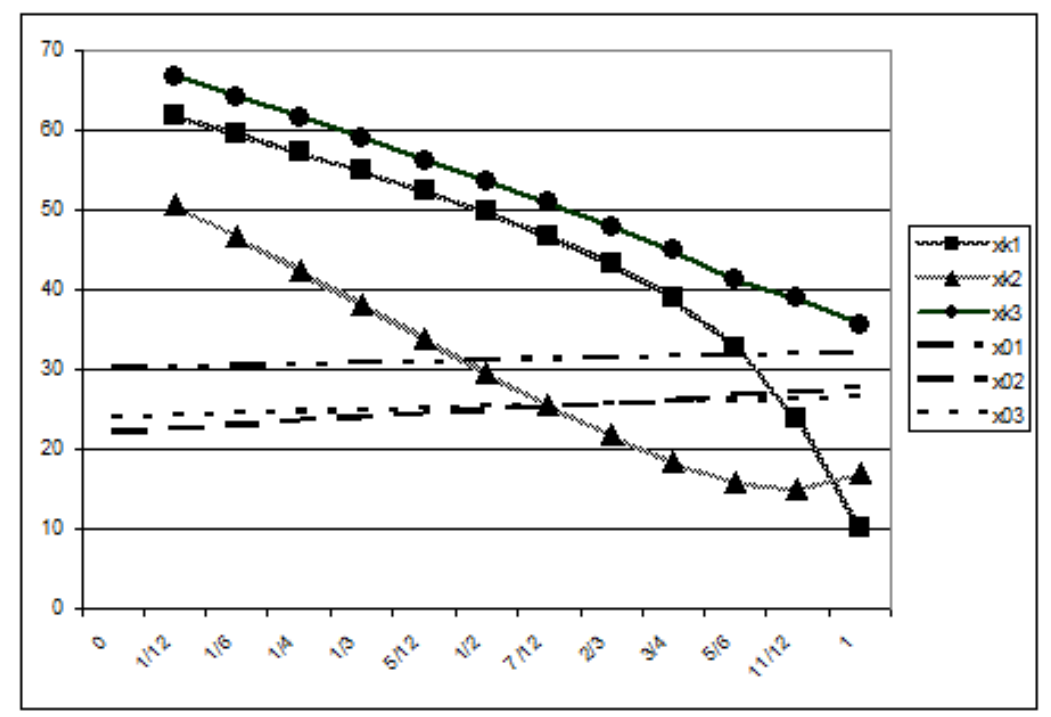

Fig. 3. The solution $\tilde{x}_{k}$ of a problem of start control for Leontieff example.

Solutions $\tilde{x}_{k}$ a problem of start control and a problem of hard starting control are the same. Comparing values of functional qualities of these problems we obtain: value of the first summand cost functional is 411930000 units, and the second is 19656,38 units (the problem of start controls), and in solving the problem of hard starting control is 411930000 units. Thus, the second term in the functional quality problems start control in magnitude less important than the first, which led to this result.

\section{Analysis of the computational efficiency of the algorithm}

To analyze the efficiency of the algorithm computing will change the calculation parameters and procedure for passing the basic procedure for the calculation of the rows of the coefficient matrix vector-polynomials $u_{k}^{\ell}$ on the example solving the problem of hard control for Leontieff type model represented Granberg example. The basic matrices of the model presented in Section 2 of this article. The $B, N_{0}, N_{1}$ and $C$ are taken as an identity matrices, $\beta=0,5$.

The results of calculations with parameter change step $r=0,5$.

Vector-polynomials of control at $r=0,5$ have the form

$$
\begin{gathered}
\tilde{v}_{k 1}^{\ell}=5 t+5 t^{2}-0,9164429 t^{3}+0,9667969 t^{4}-0,01876831 t^{7}, \\
\tilde{v}_{k 1}^{\ell}=8,28125 t-1,189575 t^{3}+0,5078125 t^{4}+0,15625 t^{6}-0,05916595 t^{7}, \\
\tilde{v}_{k 1}^{\ell}=-3,4375 t+0,625 t^{2}-1,487427 t^{3}+0,6347656 t^{4}-0,01953125 t^{6}-0,1441193 t^{7} .
\end{gathered}
$$

An approximate solutions $\tilde{x}_{k}\left(v^{\ell}, t\right)$ the problem of hard control for this example at $r=0,5$ is given in Table 8 . 
Table 8

Numerical solution $\tilde{x}_{k}\left(v^{\ell}, t\right)$ the problem of hard control for $r=0,5$

\begin{tabular}{|c|c|c|c|}
\hline $\mathrm{t}$ & $\tilde{x}_{k 1}\left(v^{\ell}, t\right)$ & $\tilde{x}_{k 2}\left(v^{\ell}, t\right)$ & $\tilde{x}_{k 3}\left(v^{\ell}, t\right)$ \\
\hline 0 & $1.800000 \mathrm{e}+001$ & $5.000000 \mathrm{e}+001$ & $3.200000 \mathrm{e}+001$ \\
\hline $1 / 12$ & $2.668857 \mathrm{e}+001$ & $6.195633 \mathrm{e}+001$ & $3.611628 \mathrm{e}+001$ \\
\hline $1 / 6$ & $2.274854 \mathrm{e}+001$ & $5.712685 \mathrm{e}+001$ & $3.722862 \mathrm{e}+001$ \\
\hline $1 / 4$ & $1.966941 \mathrm{e}+001$ & $5.326532 \mathrm{e}+001$ & $3.834109 \mathrm{e}+001$ \\
\hline $1 / 3$ & $1.741387 \mathrm{e}+001$ & $5.033933 \mathrm{e}+001$ & $3.945707 \mathrm{e}+001$ \\
\hline $5 / 12$ & $1.593343 \mathrm{e}+001$ & $4.830192 \mathrm{e}+001$ & $4.057933 \mathrm{e}+001$ \\
\hline $1 / 2$ & $1.516054 \mathrm{e}+001$ & $4.708286 \mathrm{e}+001$ & $4.171019 \mathrm{e}+001$ \\
\hline $7 / 12$ & $1.500107 \mathrm{e}+001$ & $4.658033 \mathrm{e}+001$ & $4.285170 \mathrm{e}+001$ \\
\hline $2 / 3$ & $1.532701 \mathrm{e}+001$ & $4.665296 \mathrm{e}+001$ & $4.400604 \mathrm{e}+001$ \\
\hline $3 / 4$ & $1.596925 \mathrm{e}+001$ & $4.711223 \mathrm{e}+001$ & $4.517594 \mathrm{e}+001$ \\
\hline $5 / 6$ & $1.671067 \mathrm{e}+001$ & $4.771516 \mathrm{e}+001$ & $4.636531 \mathrm{e}+001$ \\
\hline $11 / 12$ & $1.727917 \mathrm{e}+001$ & $4.815740 \mathrm{e}+001$ & $4.758001 \mathrm{e}+001$ \\
\hline 1 & $1.734082 \mathrm{e}+001$ & $4.806655 \mathrm{e}+001$ & $4.882881 \mathrm{e}+001$ \\
\hline
\end{tabular}

Table 9

Numerical solution $\tilde{v}_{k}^{\ell}\left(t_{j}\right)$ the problem of hard control for $r=0,5$

\begin{tabular}{|c|c|c|c|}
\hline$t_{j}$ & $\tilde{v}_{k 1}^{\ell}$ & $\tilde{v}_{k 2}^{\ell}$ & $\tilde{v}_{k 3}^{\ell}$ \\
\hline 0 & 0 & 0 & 0 \\
\hline $1 / 12$ & $-3.824282 \mathrm{e}-001$ & $6.894403 \mathrm{e}-001$ & $-2.829482 \mathrm{e}-001$ \\
\hline $1 / 6$ & $-6.979413 \mathrm{e}-001$ & $1.375096 \mathrm{e}+000$ & $-5.619529 \mathrm{e}-001$ \\
\hline $1 / 4$ & $-9.480440 \mathrm{e}-001$ & $2.053744 \mathrm{e}+000$ & $-8.410876 \mathrm{e}-001$ \\
\hline $1 / 3$ & $-1.133126 \mathrm{e}+000$ & $2.722815 \mathrm{e}+000$ & $-1.123735 \mathrm{e}+000$ \\
\hline $5 / 12$ & $-1.252472 \mathrm{e}+000$ & $3.380464 \mathrm{e}+000$ & $-1.412666 \mathrm{e}+000$ \\
\hline $1 / 2$ & $-1.304277 \mathrm{e}+000$ & $4.025646 \mathrm{e}+000$ & $-1.710187 \mathrm{e}+000$ \\
\hline $7 / 12$ & $-1.285674 \mathrm{e}+000$ & $4.658200 \mathrm{e}+000$ & $-2.018365 \mathrm{e}+000$ \\
\hline $2 / 3$ & $-1.192776 \mathrm{e}+000$ & $5.278930 \mathrm{e}+000$ & $-2.339372 \mathrm{e}+000$ \\
\hline $3 / 4$ & $-1.020729 \mathrm{e}+000$ & $5.889672 \mathrm{e}+000$ & $-2.675941 \mathrm{e}+000$ \\
\hline $5 / 6$ & $-7.637904 \mathrm{e}-001$ & $6.493340 \mathrm{e}+000$ & $-3.031979 \mathrm{e}+000$ \\
\hline $11 / 12$ & $-4.154229 \mathrm{e}-001$ & $7.093944 \mathrm{e}+000$ & $-3.413346 \mathrm{e}+000$ \\
\hline 1 & $3.158569 \mathrm{e}-002$ & $7.696571 \mathrm{e}+000$ & $-3.828812 \mathrm{e}+000$ \\
\hline
\end{tabular}

The calculation results $\tilde{v}_{k}^{\ell}\left(t_{j}\right)$ in the set points $t_{j}$ at $r=0,5$ shown in Table 9 .

The results of calculations with parameter change step $r=0,2$.

An approximate solutions $\tilde{x}_{k}\left(v^{\ell}, t\right)$ the problem of hard control for this example at $r=0,2$ is given in Table 10 .

Vector-polynomials of control at $r=0,2$ have the form

$$
\tilde{v}_{k 1}^{\ell}=-1,259571+0,0000512 t+2,4 t^{2}-1,22089 t^{3}+0,624128 t^{4}-0,0513792 t^{7},
$$

$\tilde{v}_{k 1}^{\ell}=-0,0002048+6,892672 t+0,8 t^{2}-1,018112 t^{3}+0,7616 t^{4}+0,016 t^{5}-0,0153856 t^{7}$,

$\tilde{v}_{k 1}^{\ell}=-0,0002048-7,160397 t+3,211776 t^{2}-0,766464 t^{3}+0,6451968 t^{4}+0,08 t^{5}-0,091136 t^{7}$. 
Table 10

Numerical solution $\tilde{x}_{k}\left(v^{\ell}, t\right)$ the problem of hard control for $r=0,2$

\begin{tabular}{|c|c|c|c|}
\hline $\mathrm{t}$ & $\tilde{x}_{k 1}\left(v^{\ell}, t\right)$ & $\tilde{x}_{k 2}\left(v^{\ell}, t\right)$ & $\tilde{x}_{k 3}\left(v^{\ell}, t\right)$ \\
\hline 0 & $1.800000 \mathrm{e}+001$ & $5.000000 \mathrm{e}+001$ & $3.200000 \mathrm{e}+001$ \\
\hline $1 / 12$ & $2.618931 \mathrm{e}+001$ & $6.192260 \mathrm{e}+001$ & $3.640835 \mathrm{e}+001$ \\
\hline $1 / 6$ & $2.232597 \mathrm{e}+001$ & $5.763341 \mathrm{e}+001$ & $3.777410 \mathrm{e}+001$ \\
\hline $1 / 4$ & $1.933502 \mathrm{e}+001$ & $5.425779 \mathrm{e}+001$ & $3.909895 \mathrm{e}+001$ \\
\hline $1 / 3$ & $1.717449 \mathrm{e}+001$ & $5.175284 \mathrm{e}+001$ & $4.038361 \mathrm{e}+001$ \\
\hline $5 / 12$ & $1.578744 \mathrm{e}+001$ & $5.005642 \mathrm{e}+001$ & $4.162796 \mathrm{e}+001$ \\
\hline $1 / 2$ & $1.509675 \mathrm{e}+001$ & $4.908135 \mathrm{e}+001$ & $4.283115 \mathrm{e}+001$ \\
\hline $7 / 12$ & $1.500000 \mathrm{e}+001$ & $4.870994 \mathrm{e}+001$ & $4.399166 \mathrm{e}+001$ \\
\hline $2 / 3$ & $1.536457 \mathrm{e}+001$ & $4.878874 \mathrm{e}+001$ & $4.510747 \mathrm{e}+001$ \\
\hline $3 / 4$ & $1.602283 \mathrm{e}+001$ & $4.912351 \mathrm{e}+001$ & $4.617627 \mathrm{e}+001$ \\
\hline $5 / 6$ & $1.676739 \mathrm{e}+001$ & $4.947443 \mathrm{e}+001$ & $4.719583 \mathrm{e}+001$ \\
\hline $11 / 12$ & $1.734644 \mathrm{e}+001$ & $4.955147 \mathrm{e}+001$ & $4.816439 \mathrm{e}+001$ \\
\hline 1 & $1.745913 \mathrm{e}+001$ & $4.900999 \mathrm{e}+001$ & $4.908123 \mathrm{e}+001$ \\
\hline
\end{tabular}

Table 11

Numerical solution $\tilde{v}_{k}^{\ell}\left(t_{j}\right)$ the problem of hard control for $r=0,2$

\begin{tabular}{|c|c|c|c|}
\hline$t_{j}$ & $\tilde{v}_{k 1}^{\ell}$ & $\tilde{v}_{k 2}^{\ell}$ & $\tilde{v}_{k 3}^{\ell}$ \\
\hline 0 & 0 & 0 & 0 \\
\hline $1 / 12$ & $-1.243577 \mathrm{e}+000$ & $5.791877 \mathrm{e}-001$ & $-5.750127 \mathrm{e}-001$ \\
\hline $1 / 6$ & $-1.198067 \mathrm{e}+000$ & $1.166672 \mathrm{e}+000$ & $-1.107429 \mathrm{e}+000$ \\
\hline $1 / 4$ & $-1.126200 \mathrm{e}+000$ & $1.760045 \mathrm{e}+000$ & $-1.598951 \mathrm{e}+000$ \\
\hline $1 / 3$ & $-1.030424 \mathrm{e}+000$ & $2.357995 \mathrm{e}+000$ & $-2.050274 \mathrm{e}+000$ \\
\hline $5 / 12$ & $-9.125002 \mathrm{e}-001$ & $2.960105 \mathrm{e}+000$ & $-2.461295 \mathrm{e}+000$ \\
\hline $1 / 2$ & $-7.735502 \mathrm{e}-001$ & $3.566847 \mathrm{e}+000$ & $-2.831154 \mathrm{e}+000$ \\
\hline $7 / 12$ & $-6.141293 \mathrm{e}-001$ & $4.179564 \mathrm{e}+000$ & $-3.158331 \mathrm{e}+000$ \\
\hline $2 / 3$ & $-4.343380 \mathrm{e}-001$ & $4.800449 \mathrm{e}+000$ & $-3.440800 \mathrm{e}+000$ \\
\hline $3 / 4$ & $-2.339759 \mathrm{e}-001$ & $5.432501 \mathrm{e}+000$ & $-3.676267 \mathrm{e}+000$ \\
\hline $5 / 6$ & $-1.274654 \mathrm{e}-002$ & $6.079479 \mathrm{e}+000$ & $-3.862494 \mathrm{e}+000$ \\
\hline $11 / 12$ & $2.294799 \mathrm{e}-001$ & $6.745823 \mathrm{e}+000$ & $-3.997725 \mathrm{e}+000$ \\
\hline 1 & $4.923392 \mathrm{e}-001$ & $7.436570 \mathrm{e}+000$ & $-4.081229 \mathrm{e}+000$ \\
\hline
\end{tabular}

The calculation results $\tilde{v}_{k}^{\ell}\left(t_{j}\right)$ in the set points $t_{j}$ at $r=0,2$ shown in Table 11.

The results of calculations with parameter change step $r=0,1$.

An approximate solutions $\tilde{x}_{k}\left(v^{\ell}, t\right)$ the problem of hard control for this example at $r=0,1$ is given in Table 12 .

Vector-polynomials of control at $r=0,1$ have the form

$$
\begin{gathered}
\tilde{v}_{k 1}^{\ell}=-10 t+0,1 t^{2}-0,83642 t^{3}+0,751 t^{4}+0,1 t^{6}-0,0841 t^{7} \\
\tilde{v}_{k 1}^{\ell}=-0,00001+7,1 t+1 t^{2}-0,99181 t^{3}+0,681 t^{4}-0,0215 t^{7} \\
\tilde{v}_{k 1}^{\ell}=-6,4 t+2,41 t^{2}-1,0052 t^{3}+0,4 t^{4}+0,1 t^{5}-0,0641 t^{7}
\end{gathered}
$$


Table 12

Numerical solution $\tilde{x}_{k}\left(v^{\ell}, t\right)$ the problem of hard control for $r=0,1$

\begin{tabular}{|c|c|c|c|}
\hline $\mathrm{t}$ & $\tilde{x}_{k 1}\left(v^{\ell}, t\right)$ & $\tilde{x}_{k 2}\left(v^{\ell}, t\right)$ & $\tilde{x}_{k 3}\left(v^{\ell}, t\right)$ \\
\hline 0 & $1.800000 \mathrm{e}+001$ & $5.000000 \mathrm{e}+001$ & $3.200000 \mathrm{e}+001$ \\
\hline $1 / 12$ & $2.592605 \mathrm{e}+001$ & $6.153523 \mathrm{e}+001$ & $3.635049 \mathrm{e}+001$ \\
\hline $1 / 6$ & $2.231883 \mathrm{e}+001$ & $5.743902 \mathrm{e}+001$ & $3.767072 \mathrm{e}+001$ \\
\hline $1 / 4$ & $1.947749 \mathrm{e}+001$ & $5.414502 \mathrm{e}+001$ & $3.896343 \mathrm{e}+001$ \\
\hline $1 / 3$ & $1.737460 \mathrm{e}+001$ & $5.162823 \mathrm{e}+001$ & $4.023080 \mathrm{e}+001$ \\
\hline $5 / 12$ & $1.597178 \mathrm{e}+001$ & $4.984928 \mathrm{e}+001$ & $4.147447 \mathrm{e}+001$ \\
\hline $1 / 2$ & $1.521337 \mathrm{e}+001$ & $4.874751 \mathrm{e}+001$ & $4.269553 \mathrm{e}+001$ \\
\hline $7 / 12$ & $1.502044 \mathrm{e}+001$ & $4.823445 \mathrm{e}+001$ & $4.389453 \mathrm{e}+001$ \\
\hline $2 / 3$ & $1.528493 \mathrm{e}+001$ & $4.818750 \mathrm{e}+001$ & $4.507163 \mathrm{e}+001$ \\
\hline $3 / 4$ & $1.586402 \mathrm{e}+001$ & $4.844399 \mathrm{e}+001$ & $4.622671 \mathrm{e}+001$ \\
\hline $5 / 6$ & $1.657455 \mathrm{e}+001$ & $4.879545 \mathrm{e}+001$ & $4.735957 \mathrm{e}+001$ \\
\hline $11 / 12$ & $1.718770 \mathrm{e}+001$ & $4.898209 \mathrm{e}+001$ & $4.847024 \mathrm{e}+001$ \\
\hline 1 & $1.742360 \mathrm{e}+001$ & $4.868766 \mathrm{e}+001$ & $4.955930 \mathrm{e}+001$ \\
\hline
\end{tabular}

Table 13

Numerical solution $\tilde{v}_{k}^{\ell}\left(t_{j}\right)$ the problem of hard control for $r=0,1$

\begin{tabular}{|c|c|c|c|}
\hline$t_{j}$ & $\tilde{v}_{k 1}^{\ell}$ & $\tilde{v}_{k 2}^{\ell}$ & $\tilde{v}_{k 3}^{\ell}$ \\
\hline 0 & 0 & 0 & 0 \\
\hline $1 / 12$ & $-8.330867 \mathrm{e}-001$ & $5.980600 \mathrm{e}-001$ & $-5.171592 \mathrm{e}-001$ \\
\hline $1 / 6$ & $-1.667180 \mathrm{e}+000$ & $1.207035 \mathrm{e}+000$ & $-1.004055 \mathrm{e}+000$ \\
\hline $1 / 4$ & $-2.503866 \mathrm{e}+000$ & $1.824652 \mathrm{e}+000$ & $-1.463425 \mathrm{e}+000$ \\
\hline $1 / 3$ & $-3.343830 \mathrm{e}+000$ & $2.449432 \mathrm{e}+000$ & $-1.897465 \mathrm{e}+000$ \\
\hline $5 / 12$ & $-4.186835 \mathrm{e}+000$ & $3.080668 \mathrm{e}+000$ & $-2.307806 \mathrm{e}+000$ \\
\hline $1 / 2$ & $-5.031710 \mathrm{e}+000$ & $3.718408 \mathrm{e}+000$ & $-2.695526 \mathrm{e}+000$ \\
\hline $7 / 12$ & $-5.876366 \mathrm{e}+000$ & $4.363423 \mathrm{e}+000$ & $-3.061195 \mathrm{e}+000$ \\
\hline $2 / 3$ & $-6.717848 \mathrm{e}+000$ & $5.017158 \mathrm{e}+000$ & $-3.404963 \mathrm{e}+000$ \\
\hline $3 / 4$ & $-7.552422 \mathrm{e}+000$ & $5.681673 \mathrm{e}+000$ & $-3.726707 \mathrm{e}+000$ \\
\hline $5 / 6$ & $-8.375737 \mathrm{e}+000$ & $6.359551 \mathrm{e}+000$ & $-4.026235 \mathrm{e}+000$ \\
\hline $11 / 12$ & $-9.183048 \mathrm{e}+000$ & $7.053794 \mathrm{e}+000$ & $-4.303569 \mathrm{e}+000$ \\
\hline 1 & $-9.969520 \mathrm{e}+000$ & $7.767680 \mathrm{e}+000$ & $-4.559300 \mathrm{e}+000$ \\
\hline
\end{tabular}

The calculation results $\tilde{v}_{k}^{\ell}\left(t_{j}\right)$ in the set points $t_{j}$ at $r=0,1$ shown in Table 13

The results of calculations with parameter change step $r=0,5$ and "feedback" scheme of main calculation procedure.

Under "feedback" scheme of basic procedure for calculating the rows of the coefficient matrix of vector polynomials $u_{k}^{\ell}$ we understand the cycle of rows of the matrix of the coefficients of vector polynomials $u^{\ell}$, beginning with the last and ending with the first, unlike "direct", where the cycle starts with the first row and finish last. The search procedure with the "feedback" loop circuit in columns is not changed.

An approximate solutions $\tilde{x}_{k}\left(v^{\ell}, t\right)$ the problem of hard control for this scheme at $r=0,5$ is given in Table 14 (inverse calculation scheme). 
Numerical solution $\tilde{x}_{k}\left(v^{\ell}, t\right)$ the problem of hard control for $r=0,5$

\begin{tabular}{|c|c|c|c|}
\hline $\mathrm{t}$ & $\tilde{x}_{k 1}\left(v^{\ell}, t\right)$ & $\tilde{x}_{k 2}\left(v^{\ell}, t\right)$ & $\tilde{x}_{k 3}\left(v^{\ell}, t\right)$ \\
\hline 0 & $1.800000 \mathrm{e}+001$ & $5.000000 \mathrm{e}+001$ & $3.200000 \mathrm{e}+001$ \\
\hline $1 / 12$ & $2.733363 \mathrm{e}+001$ & $6.345078 \mathrm{e}+001$ & $3.685485 \mathrm{e}+001$ \\
\hline $1 / 6$ & $2.323526 \mathrm{e}+001$ & $5.910245 \mathrm{e}+001$ & $3.857334 \mathrm{e}+001$ \\
\hline $1 / 4$ & $2.000795 \mathrm{e}+001$ & $5.560646 \mathrm{e}+001$ & $4.015734 \mathrm{e}+001$ \\
\hline $1 / 3$ & $1.762557 \mathrm{e}+001$ & $5.294028 \mathrm{e}+001$ & $4.160789 \mathrm{e}+001$ \\
\hline $5 / 12$ & $1.604567 \mathrm{e}+001$ & $5.106090 \mathrm{e}+001$ & $4.292518 \mathrm{e}+001$ \\
\hline $1 / 2$ & $1.520414 \mathrm{e}+001$ & $4.989894 \mathrm{e}+001$ & $4.410850 \mathrm{e}+001$ \\
\hline $7 / 12$ & $1.501010 \mathrm{e}+001$ & $4.935300 \mathrm{e}+001$ & $4.515624 \mathrm{e}+001$ \\
\hline $2 / 3$ & $1.534090 \mathrm{e}+001$ & $4.928424 \mathrm{e}+001$ & $4.606589 \mathrm{e}+001$ \\
\hline $3 / 4$ & $1.603737 \mathrm{e}+001$ & $4.951122 \mathrm{e}+001$ & $4.683416 \mathrm{e}+001$ \\
\hline $5 / 6$ & $1.689906 \mathrm{e}+001$ & $4.980495 \mathrm{e}+001$ & $4.745702 \mathrm{e}+001$ \\
\hline $11 / 12$ & $1.767969 \mathrm{e}+001$ & $4.988412 \mathrm{e}+001$ & $4.792990 \mathrm{e}+001$ \\
\hline 1 & $1.808256 \mathrm{e}+001$ & $4.941064 \mathrm{e}+001$ & $4.824787 \mathrm{e}+001$ \\
\hline
\end{tabular}

Vector-polynomials of control at $r=0,5$ have the form (inverse calculation scheme)

$$
\tilde{v}_{k 1}^{\ell}=-10 t+0,9098053 t^{3}-0,5291748 t^{4}+0,08908411 t^{7},
$$

$\tilde{v}_{k 1}^{\ell}=-0,00001907+7,812653 t+0 t^{2}-1,198521 t^{3}+0,581055 t^{4}+0,0390625 t^{5}-0,0212097 t^{7}$,

$\tilde{v}_{k 1}^{\ell}=-13,08594 t+10 t^{2}-0,8485413 t^{3}+0,5761719 t^{4}+0,15625 t^{5}-0,04581451 t^{7}$.

The calculation results $\tilde{v}_{k}^{\ell}\left(t_{j}\right)$ in the set points $t_{j}$ at $r=0,5$ and "feedback" scheme of calculations are shown in Table 15 (inverse calculation scheme).

Table 15

Numerical solution $\tilde{v}_{k}^{\ell}\left(t_{j}\right)$ the problem of hard control for $r=0,5$

\begin{tabular}{|c|c|c|c|}
\hline$t_{j}$ & $\tilde{v}_{k 1}^{\ell}$ & $\tilde{v}_{k 2}^{\ell}$ & $\tilde{v}_{k 3}^{\ell}$ \\
\hline 0 & 0 & 0 & 0 \\
\hline $1 / 12$ & $-8.328323 \mathrm{e}-001$ & $6.503699 \mathrm{e}-001$ & $-1.021513 \mathrm{e}+000$ \\
\hline $1 / 6$ & $-1.662863 \mathrm{e}+000$ & $1.296994 \mathrm{e}+000$ & $-1.906676 \mathrm{e}+000$ \\
\hline $1 / 4$ & $-2.487846 \mathrm{e}+000$ & $1.936724 \mathrm{e}+000$ & $-2.657342 \mathrm{e}+000$ \\
\hline $1 / 3$ & $-3.306132 \mathrm{e}+000$ & $2.567133 \mathrm{e}+000$ & $-3.274560 \mathrm{e}+000$ \\
\hline $5 / 12$ & $-4.116622 \mathrm{e}+000$ & $3.186512 \mathrm{e}+000$ & $-3.758516 \mathrm{e}+000$ \\
\hline $1 / 2$ & $-4.918699 \mathrm{e}+000$ & $3.793863 \mathrm{e}+000$ & $-4.108501 \mathrm{e}+000$ \\
\hline $7 / 12$ & $-5.712104 \mathrm{e}+000$ & $4.388891 \mathrm{e}+000$ & $-4.322902 \mathrm{e}+000$ \\
\hline $2 / 3$ & $-6.496760 \mathrm{e}+000$ & $4.971978 \mathrm{e}+000$ & $-4.399227 \mathrm{e}+000$ \\
\hline $3 / 4$ & $-7.272520 \mathrm{e}+000$ & $5.544132 \mathrm{e}+000$ & $-4.334164 \mathrm{e}+000$ \\
\hline $5 / 6$ & $-8.038835 \mathrm{e}+000$ & $6.106931 \mathrm{e}+000$ & $-4.123689 \mathrm{e}+000$ \\
\hline $11 / 12$ & $-8.794332 \mathrm{e}+000$ & $6.662424 \mathrm{e}+000$ & $-3.763229 \mathrm{e}+000$ \\
\hline 1 & $-9.536285 \mathrm{e}+000$ & $7.213020 \mathrm{e}+000$ & $-3.247871 \mathrm{e}+000$ \\
\hline
\end{tabular}

Figure 4 shows the solutions $\tilde{x}_{k}$ with step $r=0,5$ (solid lines) and with step $r=0,2$ (dashed lines). 


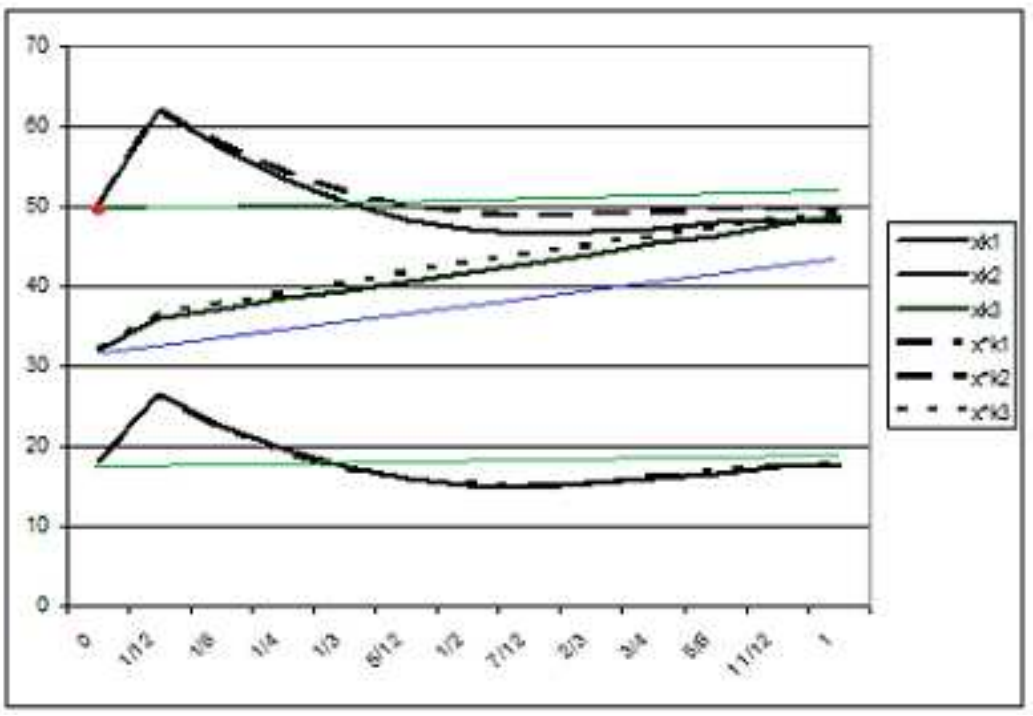

Fig. 4. Solutions $\tilde{x}_{k}$ for Granberg example with step $r=0,5$ (solid lines) and with step $r=0,2$ (dashed lines)

Figure 5 shows the solutions $\tilde{x}_{k}$ with step $r=0,5$ (solid lines) and with step $r=0,1$ (dashed lines).

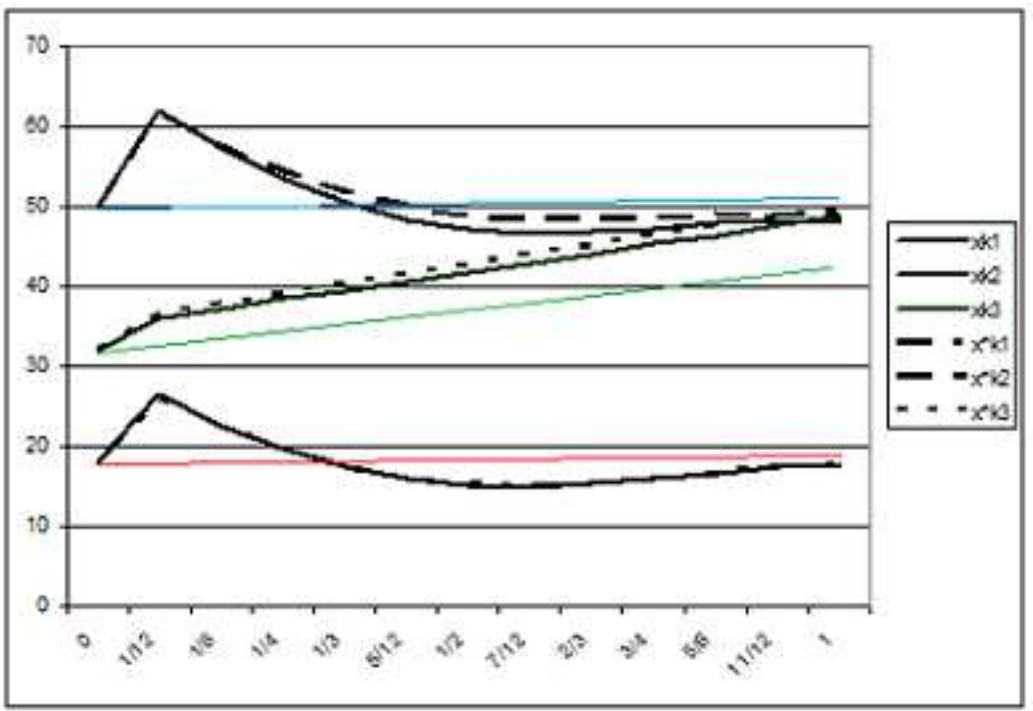

Fig. 5. Solutions $\tilde{x}_{k}$ for Granberg example with step $r=0,5$ (solid lines) and with step $r=0,1$ (dashed lines)

Figure 6 shows the solutions $\tilde{x}_{k}$ with step $r=0,5$ forward scheme (solid lines) and reverse scheme of calculations (dashed lines).

The difference between the values of the results in the value of the coefficients of polynomial vector-control functions is no more than 1 percent and this suggests the high computational efficiency of the algorithm. The most significant are the differences in values $x_{2}(t)$. However, parallelization of processes and adjustment of numerical method referred to in paragraph 1 , shortcomings of unilateral schemes, direct or reverse, will be eliminated. 


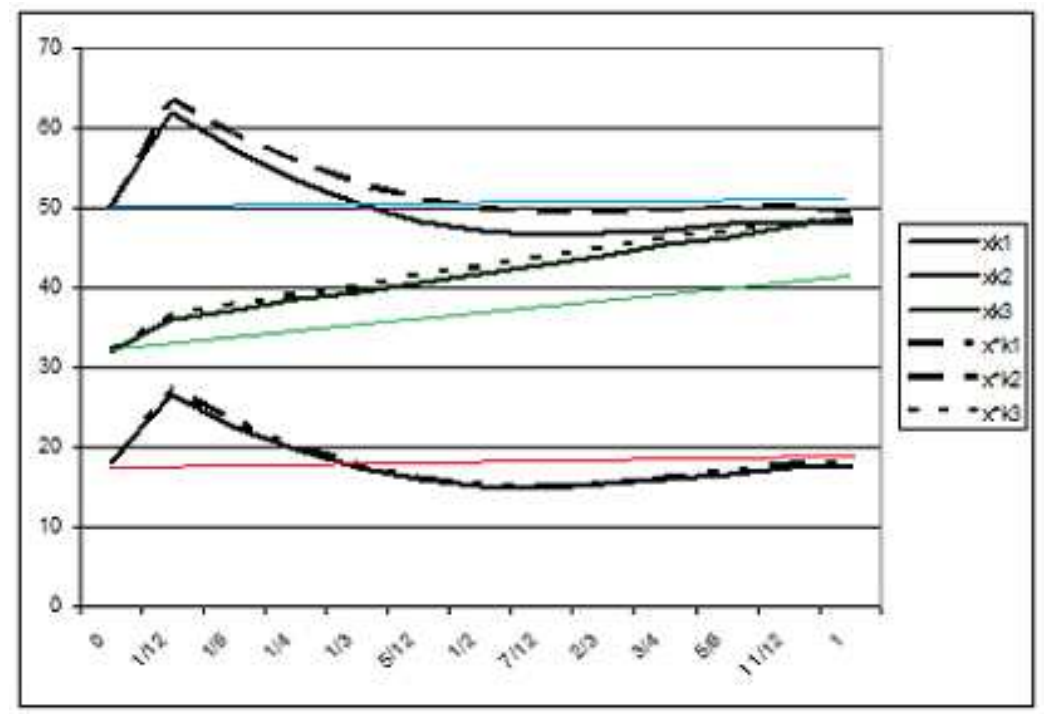

Fig. 6. Solutions $\tilde{x}_{k}$ with step $r=0,5$ forward scheme of calculations (solid lines) and reverse scheme of calculations (dashed lines).

\section{References}

1. Keller A.V. The Numerical Solution of Optimal Control Problem Degenerate Linear System of Ordinary Differential Equations with Initial Conditions Showalter Sidorov]. Bulletin of the South Ural State University. Series "Mathematical Modelling, Programming 8 Computer Software", 2008, no. 27(127), pp. 50-56. (in Russian)

2. Boyarintsev Y.E., Chistyakov V.F. [ Algebraic-Differential Systems: Methods and Research Solutions ]. Novosibirsk, Nauka Publ., 1998. (in Russian)

3. Lamour R., März R., Winkler R.How Floquet-Theory Applies to Differential-Algebraic Equations. Berlin, Institut für Mathematik der Humboldt-Universität zu Berlin, 1996.

4. Skripnik V.P. Degenerate Linear Systems. Izv. Vyssh. Uchebn. Zaved. Mat., 1982, no. 3, pp. 62-67. (in Russian)

5. Sviridyuk G.A., Brychev S.V. Numerical Solution of Systems of Equations of Leontieff Type. Izv. Vyssh. Uchebn. Zaved. Mat., 2003, no. 8, pp. 46-52. (in Russian)

6. Zil'bergleit A.S., Kopilevich Y.I. The Spectral Theory of Regular Waveguides. Leningrad, Izd. AC USSR FTI Pupl., 1983. (in Russian)

7. Shestakov A.L., Sviridyuk G.A. [A New Approach to the Measurement of Dynamically Distorted Signals] Bulletin of the South Ural State University. Series "Mathematical Modelling, Programming \& Computer Software", 2010, no. 16(182), pp. 116-120. (in Russian)

8. Granberg A.G. [Dynamic models of a National Economy]. Moscow, Ekonomika Publ., 1985. (in Russian) 
9. Leontieff V.V. [Interindustry Economics]. Moscow, Ekonomika Publ., 1997. (in Russian)

10. Sveshnikov A.G., Al'shin A.B., Korpusov M.O., Pletner Yu.D. Linear and Non-Linear Equations of Sobolev Type. Moscow, FIZMATLIT Publ., 2007. (in Russian)

11. Keller A.V. [About the Algorithm for Solving Optimal Control and Hard Control]. Programmnye Produkty $i$ Sistemy - Program Products and Systems, 2011, no. 3, pp. 170-174. (in Russian)

12. Shestakov A.L., Sviridyuk G.A. On the Measurement of the "White Noise". Bulletin of the South Ural State University. Series "Mathematical Modelling, Programming \& Computer Software", 2012, no. 27(286), pp. 99-108.

13. Gliklikh Yu.E. Investigation of Leontieff Type Equations with White Noise by the Methods of Mean Derivatives of Stochastic Processes. Bulletin of the South Ural State University. Series "Mathematical Modelling, Programming \&5 Computer Software", 2012, no. 27(286), pp. 24-34. (in Russian)

Alevtina V. Keller, Doctor of Physico-Mathematical Sciences, Docent, Dean of the Faculty of Mathematics, Mechanics and Computer Sciences, South Ural State University, Chelyabinsk, Russian Federation, alevtinak@inbox.ru.

Received April 25, 2015 